\title{
PERANCANGAN COFFEE-TABLE BOOK TENTANG OBJEK WISATA DI WILAYAH GARUT SELATAN
}

\author{
Prima Gumilang, Christine Claudia Lukman, Hendra Setiawan \\ (Email: prima.gumilang15@gmail.com) \\ Program Studi Desain Komunikasi Visual \\ Fakultas Seni Rupa dan Desain \\ Universitas Kristen Maranatha \\ JI. Prof. Drg. Surya Sumantri, MPH No. 65, Bandung, Indonesia
}

\begin{abstract}
ABSTRAK
Garut Selatan merupakan salah satu daya tarik pariwisata di Kabupaten Garut.Dalam perjalanan ke wilayah selatan Garut, wisatawan dapat menikmati keindahan pemandangan alam seperti gunung, air terjun, dan pantai. Pemerintah daerah juga mendukung pariwisata dengan memperbaiki jalur lintas selatan. Walaupun demikian daerah ini masih kurang dikenal oleh masyarakat luas sehingga jarang dikunjungi wisatawan.Pembuatan desain coffee-table bookdalam bentuk print book dan e-book merupakan salah satu upaya untuk memperkenalkan Garut Selatan pada masyarakat urban di Pulau Jawa. Buku ini dapat merepresentasikan keindahan Garut Selatan sehingga dapat membangkitkan keinginan pembaca untuk mengunjunginya.Perancangan didasarkan pada konsep yang berasal dari hasil analisis data yang dikumpulkan melalui observasi lapangan, wawancara terstruktur dan tak terstruktur, kuesioner terhadap 100 reponden.Studi literatur digunakan pula untuk mendukung data yang diperoleh di lapangan.Medium utama dalam buku ini adalah foto yang dapat menampilkan gambaran realistik dari pemandangan alam Garut Selatan.Diharapkan buku ini dapat menjadi alat informasi bagi masyarakat yang belum menikmati keindahan pemandangan alam di Garut Selatan.
\end{abstract}

Kata kunci: Garut Selatan; pariwisata; coffee-table book

\begin{abstract}
Southern Garut is one of the potential tourist attractions in the Garut region. On the way to southern Garut, tourists will be able to enjoy wonderful sceneries, such as the mountain, waterfall, and beach. The local government supports the tourism by fixing the route to this southern area. Nevertheless, it is not a well-known area so that it rarely becomes a destination of the tourists. One effort to introduce Southern Garut to Javanese urban society is through the creation of a coffee table book design (print book and e-book). This book will reveal the sides of Southern Garut rarely visited by the Javanese urban society. This book may become a representation of Southern Garut so that the target audience can see its beauty, and in the end they would decide to make it their destination. Design created is based on the concept derived from the data analysis collected through field observation, structured \& unstructured interviews, and questionnaires to 100 respondents. The literature study was also used to support the data obtained from the field. The photographs in this book are the chief medium, which will show the pictures of Southern Garut landscape. This book is meant to become a means of information for those who have not yet enjoyed the beauty of Southern Garut.
\end{abstract}

Keywords: coffee-table book; southern Garut; tourism 


\section{PENDAHULUAN}

Selain memiliki destinasi wisata seperti tempat pemandian air panas, sentra kerajinan kulit, sentra kerajinan akar wangi, batik Garutan, dan wisata kuliner, ternyata Garut masih memiliki destinasi lain yang belum banyak diketahui wisatawan yaitu kawasan Garut Selatan.

Di sepanjang wilayah Garut Selatan terbentang pemandangan alam berupa hamparan sawah, perkebunan teh, ladang sayuran, dan bukit-bukit yang dikelilingi pepohonan rindang dan diselimuti rerumputan yang terlihat seperti permadai hijau. Selain itu di wilayah ini juga terdapat Gunung Papandayan, Curug Orog, Curug Sanghyang Taraje, Leuwi Tonjong, Pantai Sayang Heulang, Pantai Santolo, dan Pantai Rancabuaya.

Salah satu usaha yang telah dilakukan oleh pemerintah daerah untuk meningkatkan kunjungan wisatawan di wilayah Garut Selatan adalah memperbaiki jalur lintas selatan.Walaupun memiliki pemandangan yang indah, dan infrastruktur yang cukup memadai namun wilayah ini tetap belum banyak diketahui sebagai salah satu destinasi wisata.

Salah satu upaya yang dapat dilakukan untuk memperkenalkan wilayah ini kepada masyarakat urban di Pulau Jawa yang senang bertamasya adalah melalui pembuatan coffee-table booktentang tempat-tempat yang menarik di Garut Selatan. Diharapkan melalui buku ini dapat merepresentasikan keindahan pemandangan Garut Selatan sehingga dapat menarik hati pembaca untuk mengunjungi daerah ini.

\section{METODE PENELITIAN}

Desain dari Coffee-table book tentang obyek wisata di wilayah Garut selatan ini melalui tiga tahapan. Tahap pertama dan kedua dilakukan pengumpulan data, yaitu melalui observasi lapangan, wawancara terstruktur dengan petugas Dinas Kebudayaan dan Pariwisata Garut; wawancara tak terstruktur dengan masyarakat setempat. Selain itu juga dilengkapi dengan data tentang pengetahuan, dan minat target audience untuk mengunjungi Garut Selatan yang diperoleh dari hasil kuesioner dari 100 orang responden. Didukung juga dengan teori diperoleh dari hasil studi literatur. 
Hasil dari data tersebut akan dianalisis dan digunakan di tahap ketiga untuk merancang konsep yang kemudian diterapkan dalam media utama (coffee-table book) dan media pendukung lainnya.

\section{Coffee-table book}

Coffee-table book adalah sebuah buku dengan banyak gambar, dapat berupa foto atau ilustrasi, yang dirancang untuk dinikmati dengan cara dilihat daripada dibaca, oleh karena itu Coffeetable book dilengkapi dengan caption, dan teks singkat. Di negara maju, buku ini biasanya ditempatkan pada sebuah meja di area hotel atau cafe untuk tamu dan dapat digunakan sebagai bahan diskusi ringan. Pada umumnya bersifat non-fiksi, dan merupakan photo-book. Buku ini ditujukan bagi siapa saja yang ingin membaca buku dengan konten yang ringan. (www.collinsdictionary.com/2017)

\section{Landscape Photography}

Landscape photography adalah genre fotografi yang menjadikan pemandangan alam sebagai objek utamanya. Pada umumnya landscape photography digunakan untuk membangkitkan kenangan pemirsa saat berada di luar ruangan, terutama saat berwisata. Kadang-kadang juga digunakan untuk memperlihatkan gaya hidup outdoor yang melibatkan alam dan elemenelemennya yang terlepas dari kungkungan kehidupan artifisial di kota besar (Caputo, 2007). Dapat dikatakan bahwa tujuan terpenting dari landscape photography adalah mengajak pemirsa mengapresiasi keindahan alam dan melestarikannya.

Teknik dasar untuk menghasilkan foto pemandangan alam yang baik, menurut Abdi (2012) adalah sebagai berikut:

1. Memaksimalkan depth of field sehingga seluruh bagian foto fokus atau tajam.

2. Memiliki focal point yaitu bagian foto yang menarik sehingga dilihat pertama kali dilihat sebelum mata meng-eksplorasi detail dari keseluruhan foto. Focal point dapat berupa bangunan kecil yang unik di tengah dataran kosong, pohon yang berdiri sendiri, batu, manusia, hewan, atau silhouette yang terlihat kontras dengan latar belakang.

3. Memanfaatkan garis dan pola untuk menggiring mata mengeksplor foto lebih jauh. Pola dapat berupa deretan pohon, bayangan, tangga, dan lain sebagainya. Garis-garis dapat memberikan kesan skala ukuran dan kedalaman ruang. 
4. Menangkap momen dan gerakan karena landscape photography tidak hanya menampilkan gambar langit, bumi, gunung, tapi juga semua elemen alam yang diam maupun bergerak seperti air terjun, aliran sungai, dan lain sebagainya.

5. Memanfaatkan golden hours dan blue hours. Saat terbaik untuk melakukan pemotretan alam adalah saat matahari terbit dan terbenam. Golden hours adalah saat 1 hingga 2 jam sebelum matahari terbenam, atau 1 hingga 3 jam setelah matahari terbit. Pada saat ini sinar maahari akan memberi warna keemasan pada objek foto, dan menghasilkan bayangan yang panjang yang dapat menjadi leading lines. Blue hours terjadi 20-30 menit setelah matahari terbenam yang masih menyisakan warna kebiruan, atau pada saat langit berwarna biru.

\section{PEMBAHASAN}

Daerah Garut Selatan Memiliki pemandangan alam yang asri, dengan beragam objek wisata potensial. Objek wisata Pantai di Garut Selatan dari Bandung dan Jakarta jaraknya lebih dekat daripada ke pantai Pangandaran dan Pelabuhan Ratu. Selain itu terdapat berbagai macam rumah makan Sunda yang memiliki harga terjangkau, hal tersebut menjadi Kekuatan dari perancangan karya ini. Namun ditemukan juga beberapa kelemahan, yaituKurangnya tempat penginapan di daerah Garut Selatan, hal tersebut membuat daerah wisata kurang dipromosikan. Namun didukung dengan gaya hidup masyarakat saat ini yang gemar berwisata membuka peluang bagi para investor untuk berinvestasi untuk mendukung objek wisata di Garut Selatan

Berdasarkan analisis data, Segementing, Targeting dan Positioning dari perancangan karya ini, adalah sebagai berikut:

1. Segmentasi dari perancangan karya ini adalah:

a. Demografi: pria dan wanita remaja akhir (17-25 tahun) dan dewasa awal (26-35 tahun) yang tinggal di Jawa Barat.

b. Status Ekonomi: Status ekonomi B, A, berprofesi sebagai Pelajar, pegawai, wiraswasta, dengan pendapatan Rp. 2,5 juta - > Rp. 5 juta.

c. Psikografi: Menyukai traveling, mencintai alam, suka menjelajah daerah baru. 


\section{Targeting dari Perancangan ini terbagi menjadi dua, yaitu:}

Target primer dari perancangan ini adalah kelompok dewasa awal (usia 26 - 35 tahun), sedangkan target sekunder adalah remaja akhir (usia 17 - 25 tahun).

3. Positioning dari Perancangan karya ini adalah sebagai coffee-table book yang mengangkat Garut Selatan sebagai destinasi wisata yang memiliki beragam objek wisata yang masih alami. Perjalanan ke Garut Selatan dapat dikatakan sebagai "A Journey to the Nature".

Konsep Komunikasi dari desain coffee-table book ini ingin menampilkan kesan alami, bersih, sederhana dan elegance.

Konsep Kreatif yang ingin dikomunikasikan diwujudkan dengan cara menggambarkan secara langsung keindahan dari obyek-obyek wisata di daerah Garut Selatan melalui teknik Photography landscape yang dilayout sederhana dan diperkuat dengan dekorasi berupa motif batik Lereng Jaksa yang merupakan batik khas Garut sebagai aksen untuk menampilkan identitas budaya setempat.

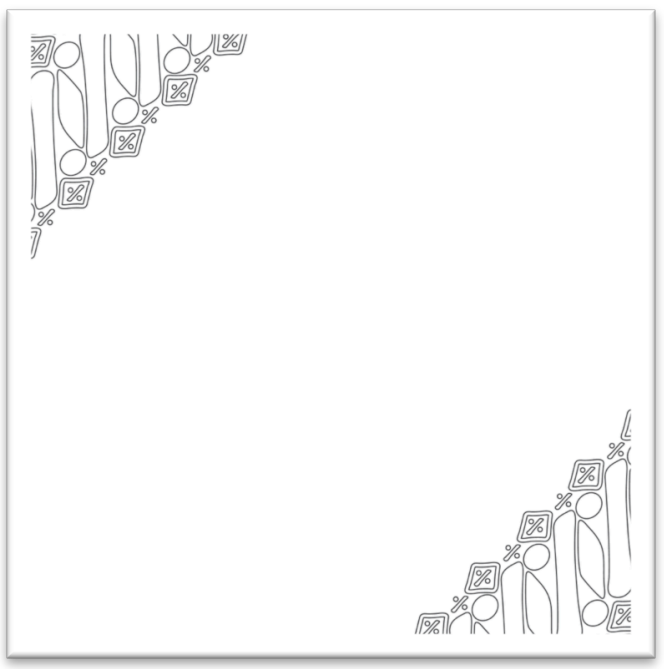

Gambar 1. Motif Lereng Jaksa

Sumber: Penulis, 2016 
Adapun huruf yang digunakan adalah:

\title{
Frutiger ABCDEFGHIJKLMNO PQRSTUVWXYZÀÅÉî abcdefghijkImnopq rstuvwxyzàåéĩõü\& 1234567890 (\$f.,!?) \\ Forlunala
}

\author{
ABCDEFGI HIIKLM \\ NOPQRSTUVWXYZ \\ abcdefghijklm \\ nopqrstuvwxyz \\ (0123456789!?\#
}

Dominasi warna putih ditempatkan pada bidang layout selain foto untuk memberi kesan bersih

Media utama yang digunakan untuk mendokumentasikan foto-foto yang menggambarkan keadaam alam di wilayah Garut Selatan adalah sebuah coffee-table bookdalam bentuk printbook dan e-book. Buku ini memuat lebih banyak foto dibandingkan tulisan agar pembaca bisa menikmati keindahan alam di Garut Selatan.Selain media utama terdapat juga media pendukung untuk mempromosikan buku ini pada masyarakat seperti poster, $x$-banner, dan lainlain.

Konsep kreatif yang telah dipaparkan diatas divisualkan dalam Hasil Karya sebagai berikut:

Coffee-table bookberukuran $20 \mathrm{~cm}$ x $20 \mathrm{~cm}$; menampilkan foto-foto yang diambil di wilayah Garut Selatan. Buku ini menggunakanhard cover art paper, sedangkan halaman isi menggunakan art paper 210 gram.

Cover buku didominasi oleh foto yang diambil di kaki Gunung Papandayan. Judul buku menggunakan font Fortunata dan disusun secara simetris. 


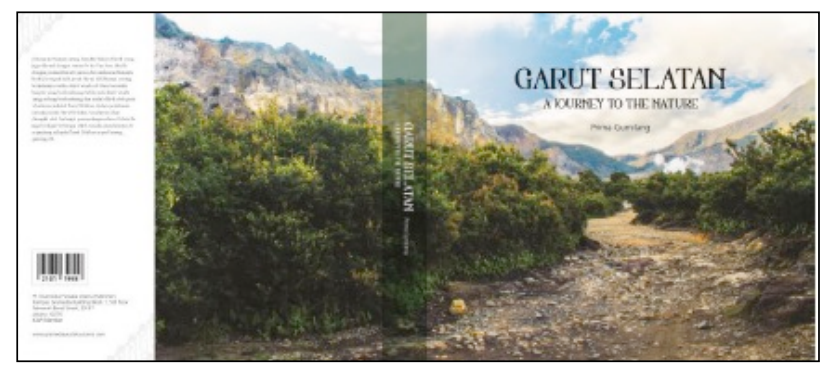

Gambar 2. Back Cover dan Font Cover Sumber: Penulis, 2016

Foto pada cover ini memanfaatkan prinsip-prinsip dasar landscape photography yaitu memaksimal-kan depth of field sehingga seluruh bagian foto fokus, memiliki focal point yaitu bagian pertemuan lereng dari dua tebing yang miring, memanfaatkan pola (batu, dan dedaunan) untuk menggiring mata mengeksplorasi foto menuju focal pointyang berada di bagian titik hilang perspektif. Pemotretan pemandangan di kaki Gunung Papandayan dilakukan pada saat langit biru (blue hours). Tipografi ditempatkan pada bagian cover depan (judul), punggung buku, dan cover belakang (teks singkat yang menjelaskan isi buku).

Halaman daftar isi (table of contents) memuat gambar pemandangan pantai dan informasi mengenai daftar isi dari buku.Pada gambar ini batu-batuan dan tumbuhan pada tebing berfungsi sebagai tekstur yang mengarahkan pandangan pada bagian kanan foto yang ditutupi kotak putih yang memuat daftar isi buku.Huruf yang digunakan adalah Frutiger CE 45 Light yang berkesan sederhana dan mudah terbaca.

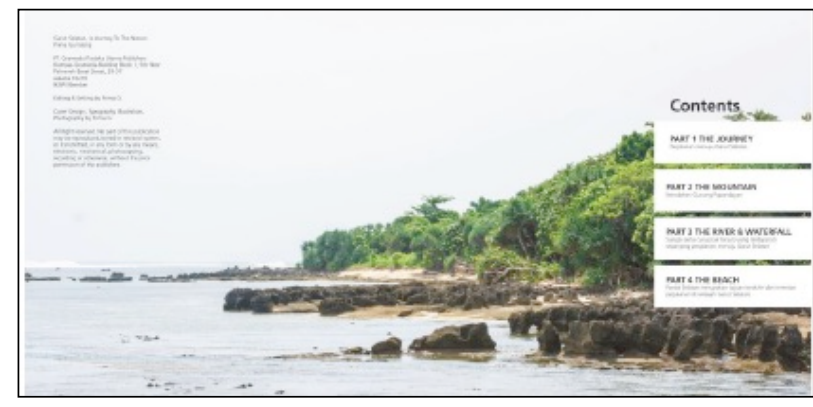

Gambar 3. Halaman daftar isi Sumber: Penulis, 2016

Halaman pendahuluan menampilkan gambar seseorang sedang menyeberangi jembatan sebagai metafora bagian pendahuluan yang mengantarkan seseorang pada suatu tujuan.Font 
yang digunakan adalah Frutiger CE 45.Teks ditempatkan di bagian kanan gambar dan disusun rata kiri.

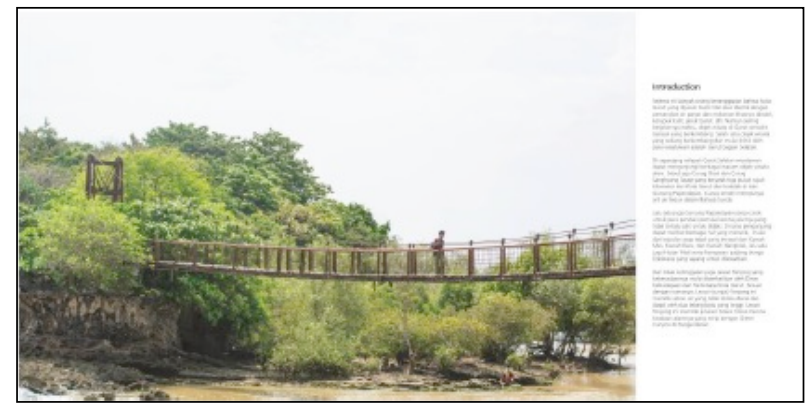

Gambar 4. Halaman pendahuluan Sumber: Penulis, 2016

Halaman pembuka setiap bab didominasi foto pemandangan yang sesuai dengan wilayah yang dibahas, dilengkapi kotak putih berisi judul bab dan dekorasi motif batik. Halaman pembuka bab 1 memperlihatkan gambar pemandangan di sawah, bab 2 pemandangan di Gunung Papandayan, bab 3 pemandangan di Curug Orok, dan bab 4 pemandangan di Pantai Sayang Heulang.

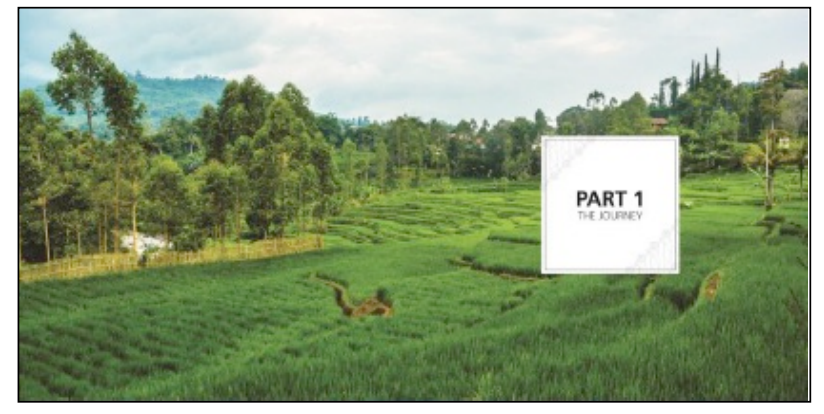

Gambar 5. Halaman pembuka bab 1 Sumber: Penulis, 2016

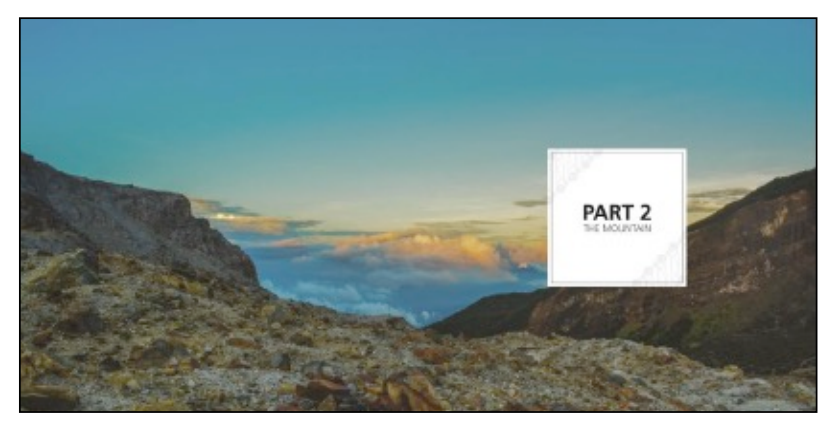

Gambar 6. Halaman pembuka bab 2 Sumber: Penulis, 2016 


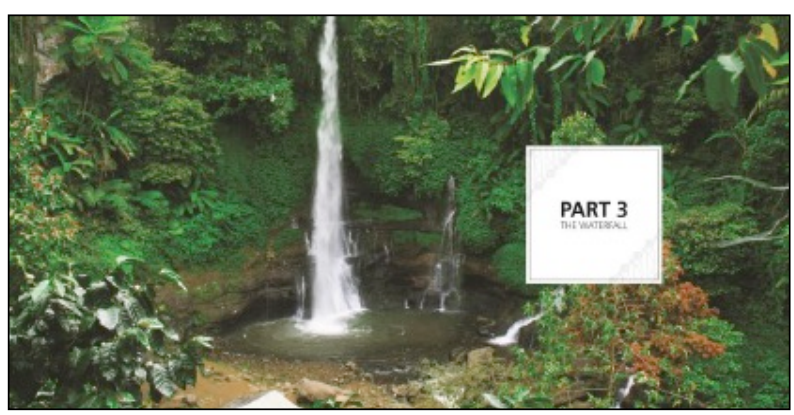

Gambar 7. Halaman pembuka bab 3 Sumber: Penulis, 2016

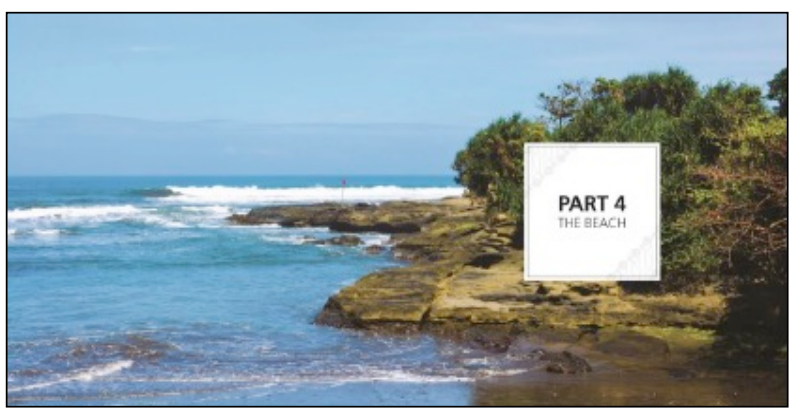

Gambar 8. Halaman pembuka bab 4 Sumber: Penulis, 2016

Foto-foto yang terdapat pada halaman pembuka bab memiliki depth of field yang luas sehingga seluruh bagian foto tajam. Pemotretan dilakukan pada saat blue hours sehingga langit terlihat biru, kecuali pada halaman pembuka bab 2 saat golden hours.

Layout dari halaman isi dari setiap bab didominasi oleh foto yang menempati $3 / 4$ halaman, dan teks penjelasan singkat di bagian yang tidak diisi gambar. Teks dapat terdapat di bagian kiri maupun kanan gambar. Kadang-kadang ditampilkan pula foto close-up dari bagian foto utama yang dianggap menarik. Contohnya dapat dilihat pada gambar dibawah ini:

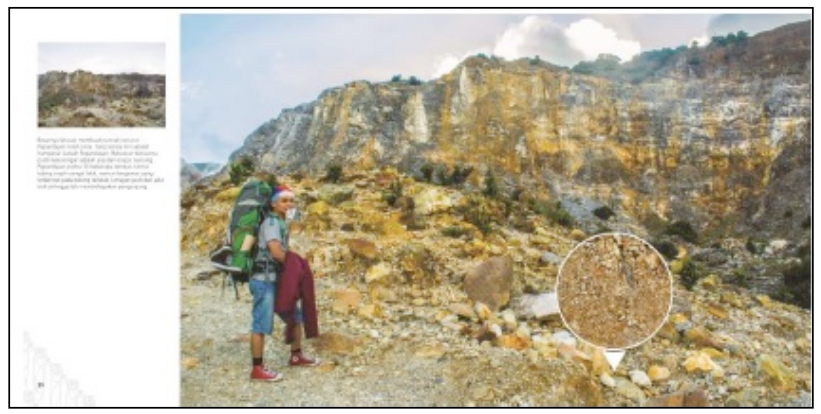

Gambar 9. Contoh halaman isi bab 2 Sumber: Penulis, 2016 


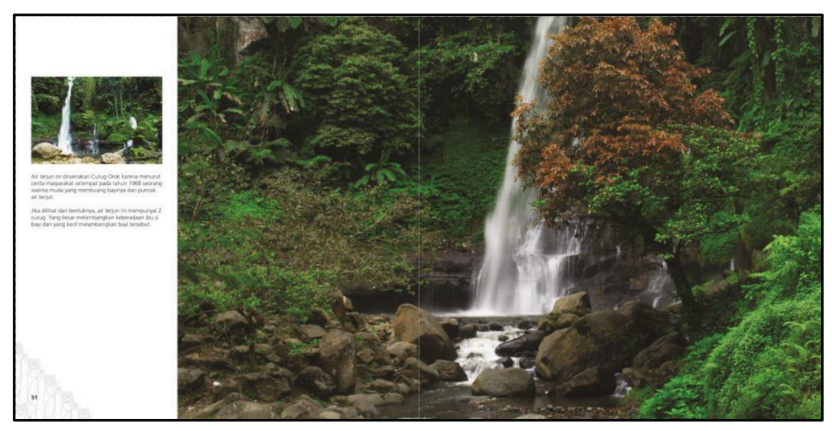

Gambar 10. Contoh halaman isi bab 3 Sumber: Penulis, 2016

Media pendukung digunakan untuk mendukung promosi peluncuran buku, promosi buku di majalah, dan sosial media. Dalam kegiatan promosi peluncuran buku, media yang digunakan adalah poster dan $x$-banner. Poster menampilkan foto buku di atas latar putih.Di bagian bawah diperlihatkan contoh dari 2 halaman isi buku tersebut.Headline ditempatkan di bagian paling bawah bersama logo mandatory. X-banner menggunakan latar putih yang memuat foto buku di bagian atas, dan contoh beberapa halaman isi di bagian bawahnya. Headline ditempatkan di bagian bawah. Warna latar putih pada poster dan $x$-banner dipilih agar foto pemandangan dapat terlihat jelas dan menonjol.

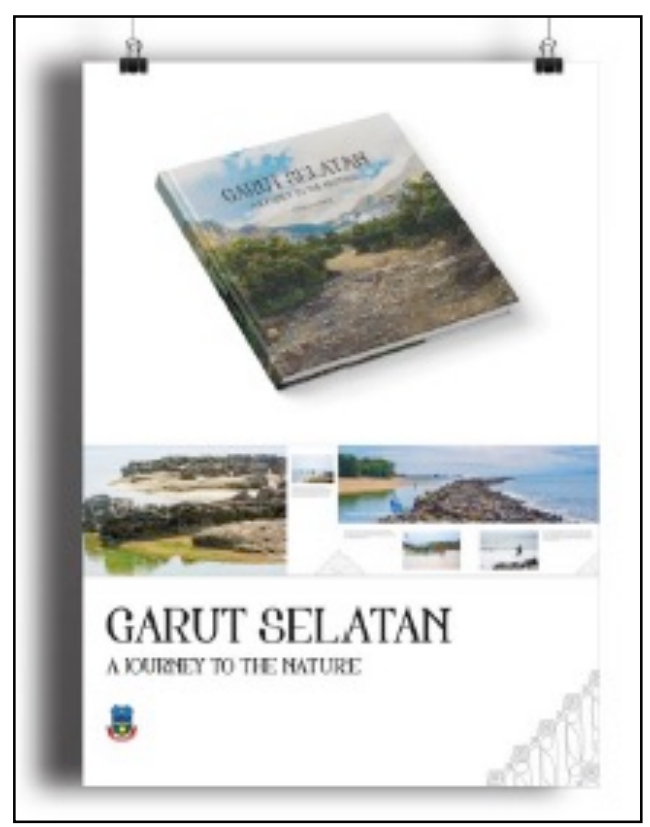

Gambar 11. Poster A2

Sumber: Penulis, 2016 


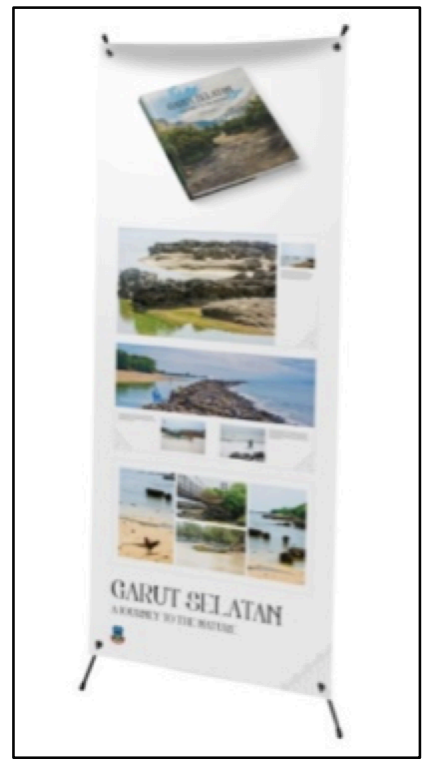

Gambar 12. X-Banner Sumber: Penulis, 2016

Iklan coffee-table book "Garut Selatan: Journey to the Nature" dimuat di majalah National Geographic (1 halaman), dan di media sosial Instagram (ukuran 1080 pixel x 1080 pixel) dan Facebook (ukuran 851 pixel x 351 pixel).

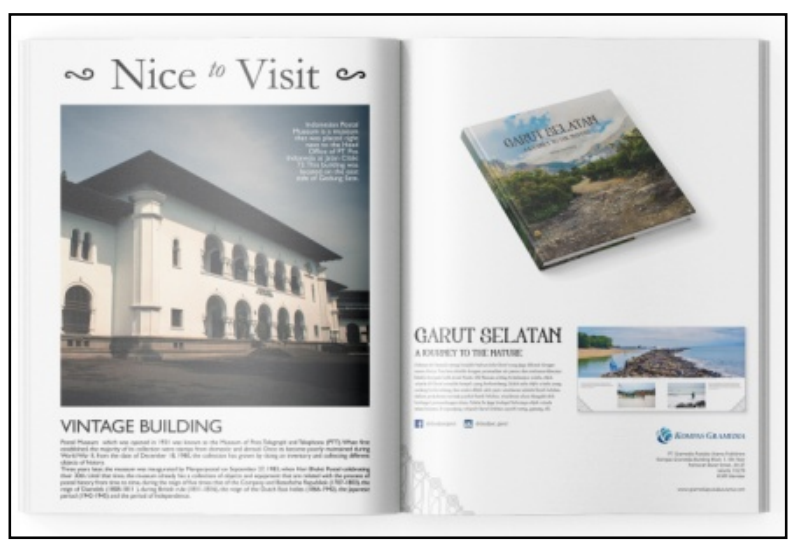

Gambar 13. Iklan Majalah

Sumber: Penulis, 2016 


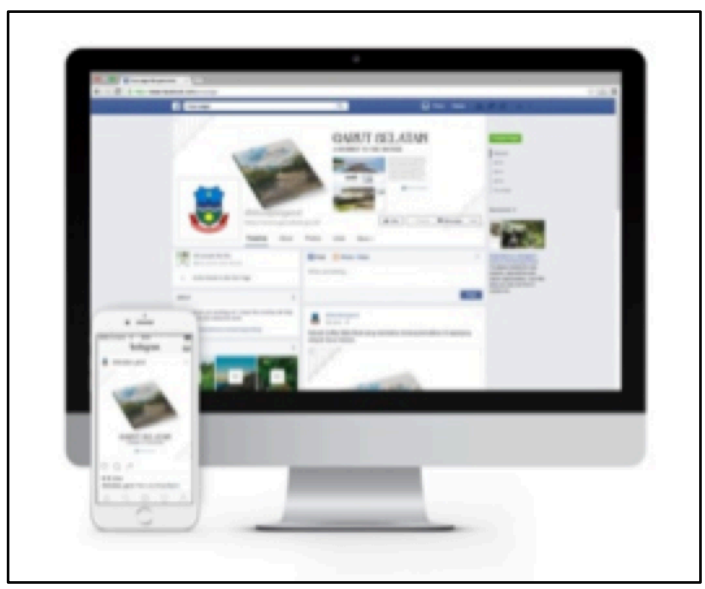

Gambar 14. Facebook \& Instagram Sumber: Penulis, 2016

Pembatas buku berukuran $5 \mathrm{~cm} \times 15 \mathrm{~cm}$ diselipkan dalam buku sebagai souvenir.

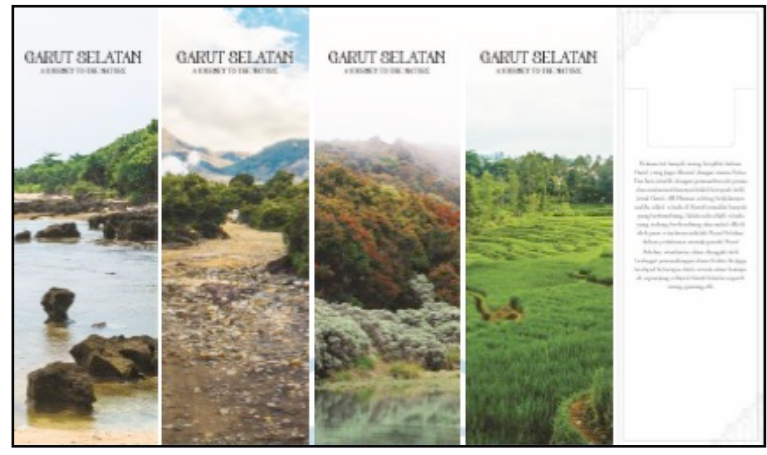

Gambar 15. Pembatas Buku Sumber: Penulis, 2016

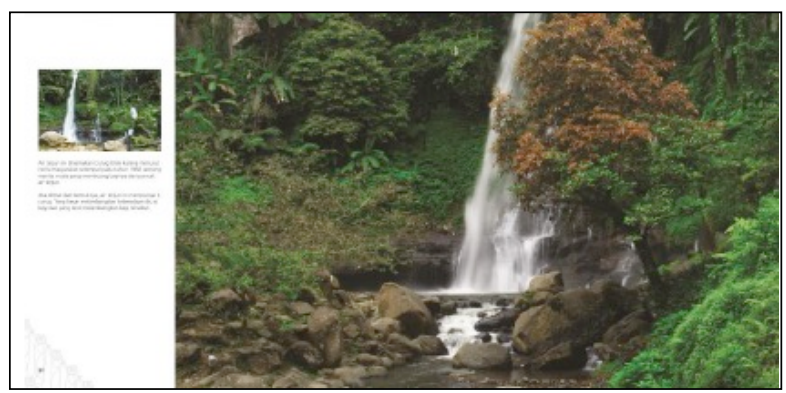

Gambar 16. Contoh halaman isi bab 3 Sumber: Penulis, 2016 


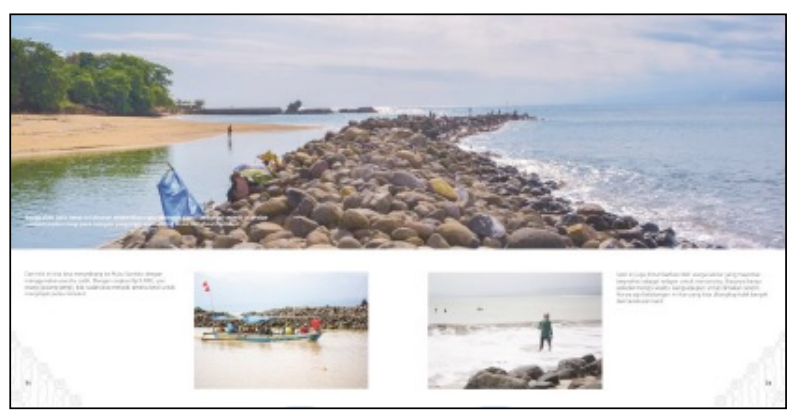

Gambar 17. Contoh halaman isi bab 4 Sumber: Penulis, 2016

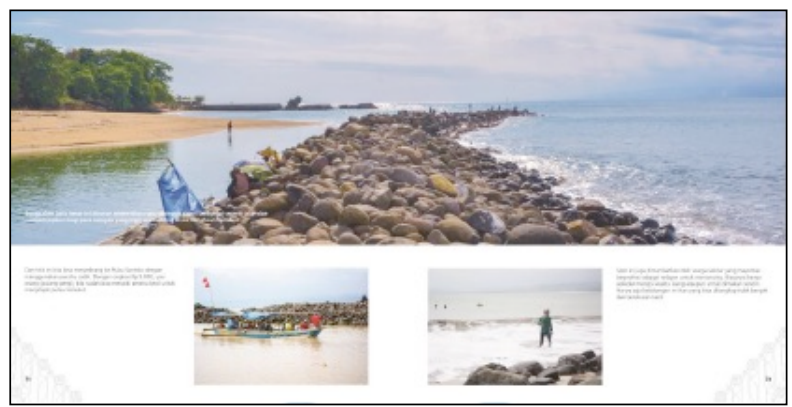

Gambar 18. Contoh halaman isi bab 5 Sumber: Penulis, 2016

\section{PENUTUP}

Berdasarkan hasil observasi, wawancara dan kuesioner terungkap bahwa Garut Selatan memiliki pemandangan yang indah namun belum banyak diketahui oleh masyarakat.Untuk mengenalkan wilayah ini pada target audience (target primer yaitu kelompok dewasa, dan target sekunder yaitu remaja akhir) perlu dibuat media yang berfungsi untuk memberikan informasi visual dan verbal.

Media yang paling sesuai adalah coffee-table bookdalam bentuk print-book dan e-book.dengan cara memperlihatkan keindahan alam di kawasan selatan Garut yang meliputi wilayah pertanian (sawah, dan ladang), gunung, air terjun, dan pantai. Coffee-table book sesuai untuk target audience yang menyukai bacaan ringan karena lebih banyak menampilkan gambar daripada tulisan.

coffee-table bookperlu memperhatikan kaidah-kaidah desain buku yang baik seperti penggunaan grid, pemilihan huruf yang jelas terbaca, dan tata letak agar terlihat menarik. Foto 
dibuat sesuai aturan dasar landscape photography agar menarik dan dapat menampilkan keindahan pemandangan di wilayah ini.

Perlu diadakan acara peluncuran buku disertai diskusi ringan agar keberadaan buku ini dapat diketahui masyarakat, untuk keperluan itu perlu dibuat media pendukung seperti poster, iklan majalah, dan iklan di media sosial. Diharapkan melalui buku ini wilayah Garut Selatan dapat lebih dikenal oleh masyarakat.

\section{DAFTAR PUSTAKA}

Frye, Michael. (2009). Digital Landscape Photography. First Edition. Lewes, United Kingdom: The Ilex Press Limited.

Muench, Marc. (2011). Exploring North American Landscapes. First Edition. Santa Barbara, California: Rocky Nook Inc.

Sumarsono, Hartono, Helen Ishwara, L.R. Supriyapto Yahya, dan Xenia Moeis. (2013). Benang

Raja, menyimpul Keelokan Batik Pesisir. Jakarta: Kepustakaan Populer Gramedia.

\section{Sumber lain}

Caputo, Robert, "Landscape Photography Tips", National Geographic, August 2007, (from Photography Field Guide: Landscapes and Ultimate Photography Field Guide: Landscapes).

Ellement, Brad (U.K.) "Featured Artist: Brad Ellement", Landscape Photography Magazine, 2014 Edition ("The Big Free Edition"), 56.

McNeal, Kevin with interviewer Dimitri Vasileiou, "In Conversation... Kevin McNeal", Landscape Photography Magazine, 2014 Edition ("The Big Free Edition"), 34

Vasilakis, Konstantinos, "Portfolio", Landscape Photography Magazine, 2014 Edition ("The Big Free Edition"), 88.

\section{Sumber Online}

http://carterlandscapephotography.com.au/what-is-landscape-photography//4/9/2016/09.00 https://www.collinsdictionary.com/dictionary/english/coffee-table-book/2/02/2017/14.00 http://www.garutkab.go.id/pub/static_menu/detail/sekilas_visi_bupati/4/11/2017/12.00 
http://www.gq.com/gallery/what-your-favorite-book-says-about-you-coffee-tablebooks/4/11/2017/12.30

http://www.ranker.com/list/20-greatest-coffee-table-books-of-all time/superphotog/1/10/2016/10.00 